\title{
Identificação de Fatores Críticos de Sucesso para Monitoramento do Nível de Satisfação de Hóspedes de Hotéis
}

\author{
Critical Success Factors Identification \\ for Satisfaction Level Monitoring on Luxury Hotels
}

\author{
Silvio Augusto Minciotti ${ }^{1}$ \\ Filippo Santolia ${ }^{2}$ \\ Conceição Aparecida R. Palma Kaspar ${ }^{3}$
}

\begin{abstract}
Resumo
Vive-se um momento econômico em que verdadeiras guerras são travadas pela preferência dos clientes: é a competitividade em mercados extremamente concorridos, resultado de vários fatores, mas principalmente da globalização. Essa é a realidade de diversos segmentos, inclusive na prestação de serviços, especialmente as organizações hoteleiras. É necessário não apenas atender o cliente, mas encantá-lo e surpreendê-lo, e para isso é fundamental conhecer aquilo que representa valor para o cliente: os itens que ele deseja e valoriza e que fazem com que prefira esta ou aquela empresa. Este artigo tem como objetivo a identificação de fatores críticos de sucesso e seus respectivos atributos para monitoramento do nível de satisfação de clientes de hotéis. Partindo do referencial teórico disponível acerca do que é satisfação de clientes para uma organização hoteleira e a partir de entrevistas com especialistas da área, acadêmicos e profissionais do mercado, elaborou-se um questionário que relaciona os prováveis itens considerados como fatores críticos de sucesso e respectivos atributos numa organização hoteleira. A aplicação foi realizada com os hóspedes de um hotel categoria super luxo, localizado na cidade de Campinas. O artigo apresenta também os resultados dessa aplicação.
\end{abstract}

Palavras-chaves: satisfação de clientes; fatores; atributos; hotel.

\begin{abstract}
The current economic moment are facing real wars to get the customers preferences: it is the competition on extremely crowded markets, resulting from several factors, but mainly because of the globalization. This is the reality on several segments, including services, especially on the hotels organizations. It is necessary not only to attend the customer, but to enchant and to surprise them, to make it happen is primordial to know what represents value to them: the items they desire, valorize and are responsible for their decision about what company to choose. This article objective is the identification of critical successful factors and its respective attributes to monitoring the satisfaction level of hotels customers. Considering the available literature about customer's satisfaction in hotels organizations, interviews with specialists, academics and market professionals, it was prepared a questionary which lists the probable items considered as critical success factors and its respective attributes. The

\footnotetext{
1 Doutor em Administração pela Faculdade de Economia, Administração e Contabilidade - FEA - USP, Professor de Graduação e Pós-graduação na Universidade Municipal de São Caetano do Sul - IMES, Secretário Executivo da Agência de Desenvolvimento Econômico do Grande ABC e Consultor em Marketing. E-mail: silvio.minciotti@imes.edu.br

${ }^{2}$ Mestre em Administração pela Universidade IMES, Professor de Graduação no Centro Universitário SENAC. E-mail: filippo_santolia@yahoo.com.br

${ }^{3}$ Mestre em Administração pela Universidade IMES, Coordenadora Adjunta do Curso de Administração das Faculdades Integradas Torricelli. E-mail: rpkass@terra.com.br
} 
application was done with the guests of super luxury hotel located in the city of Campinas. The article also presents the results of this application.

Keywords: customer satisfaction; factors; attributes; hotel.

\section{Introdução}

Sabe-se hoje, que numa era globalizada, prestadores de serviços, especialmente as organizações hoteleiras, convivem em um ambiente de alta competitividade, buscando eficácia para as suas ações estratégicas e operacionais. A necessidade de conquista do cliente não se altera, e sim, a sua forma de execução. Conquistar, atualmente, não reside somente em atender, pois, em princípio, todos estão atendendo. Neste momento atender inclui inovar, encantar e surpreender e isso pressupõe conhecer as expectativas dos clientes para executar ações que permitam não apenas atendê-las, mas acima de tudo, superá-las.

Para uma organização se manter no topo do seu mercado, de acordo com Day (2001), precisa estar sempre lançando grandes inovações. Mas a diferença para estar orientado para o mercado origina-se na demonstração da capacidade mais elevada para compreender, atrair e manter clientes importantes.

Um dos maiores problemas das organizações hoteleiras é a correta identificação das ações e melhorias nas quais devem investir para obter os resultados esperados. Nesse cenário o problema que se apresenta é: quais esforços empreendidos por um hotel são valorizados por seus clientes?

Este artigo tem como objetivo identificar fatores críticos de sucesso e respectivos atributos, para monitoramento do nível de satisfação de hóspedes de hotéis de negócios, alinhados com as estratégias das organizações hoteleiras.

Para tanto foi realizada uma pesquisa que atingiu o objetivo proposto e, também, validou os resultados encontrados, aplicando-os a uma pesquisa do tipo "Medição do Nível de Satisfação de Clientes”, em um hotel de categoria super luxo. 


\section{Recomendações para a medição do nível de satisfação de clientes}

Dentre as várias definições sobre o conceito de serviços apresentado por diversos autores, parece-nos que a que melhor se adequa ao setor de hotelaria é a apresentada por Kotler (2000, p. 448) ao discorrer que "serviço é qualquer ato ou desempenho, essencialmente intangível, que uma parte pode oferecer a outra e que não resulta na propriedade de nada. A execução de um serviço pode estar ou não ligada a um produto concreto”.

A essa situação, aplica-se indubitavelmente a afirmação de Lovelock e Wright (2003), em que a satisfação do cliente desempenha um papel particularmente crítico em ramos altamente competitivos, onde há uma enorme diferença entre a fidelidade de clientes meramente satisfeitos e a de clientes completamente satisfeitos - ou encantados, e os autores acrescentam, ainda, que para melhorar os níveis de satisfação do cliente, uma empresa deve inicialmente descobrir o quanto seus clientes atuais estão realmente satisfeitos ou insatisfeitos.

Reveste-se, pois, de fundamental importância, a medida da satisfação dos clientes no ramo de serviços. Nesse item em especial, levam vantagens às empresas que oferecem alguns tipos de produtos passíveis de reparo, substituição e garantias, os quais podem ser apresentados ao cliente, antes que este faça sua opção definitiva.

A seqüência a seguir, segundo Lovelock e Wright (2003), mostra os passos envolvidos na identificação de uma estratégia eficaz de serviço:

- Determinar os atributos mais importantes do serviço para atender e superar as expectativas dos clientes;

- Determinar os atributos importantes do serviço, nos quais os concorrentes são mais vulneráveis;

- Determinar as capacidades e potenciais de serviços da empresa;

- Avaliar competências e incompetências do serviço, pontos fracos e fortes dos recursos, reputação do serviço, sistema de crenças e "razão de ser”;

- Desenvolver uma estratégia de serviço que se dirija às necessidades importantes e permanentes do cliente, que explore pontos vulneráveis da concorrência e se ajuste às capacidades e potencial da empresa.

Assim, o primeiro passo para definir uma estratégia é identificar as necessidades dos clientes e as que não estão sendo atendidas adequadamente pela empresa. A partir da identificação e 
da análise das ações necessárias para não apenas atender, como principalmente, atender melhor do que os concorrentes, as empresas poderão desenvolver uma vantagem competitiva.

Conquistar o cliente através da oferta de qualidade superior é um caminho ao desenvolvimento de vantagens competitivas. Para que isso se torne viável, no entanto, faz-se necessário entender o que significa qualidade e como é percebida pelos clientes.

A manutenção de um alto nível de qualidade, segundo Kotler, Hayes e Bloom (2000), não é uma tarefa simples para as empresas prestadoras de serviços, apesar da dificuldade em avaliar o verdadeiro nível de qualidade de um serviço, uma vez que as idéias de diversos profissionais e clientes, do que é qualidade, podem variar muito. As empresas, comenta o autor, deverão monitorar continuamente seus níveis de qualidade, para mantê-los elevados e resistir à pressão para baixá-los devido à necessidade, muitas vezes, de enfrentar preços menores da concorrência.

O autor ressalta, ainda, que no desenvolvimento de uma vantagem competitiva, para distinguir seus serviços dos concorrentes, as empresas utilizam estratégias de posicionamento, que contemplam fatores como: atributos, preço, qualidade ou outros com relação direta com o tipo de serviço, o público-alvo e a concorrência.

É por meio do posicionamento do produto, segundo Mowen e Minor (2003), que uma empresa influencia o modo como os consumidores percebem as características de uma marca em relação aos concorrentes. O objetivo do posicionamento é influenciar a demanda, criando um produto com características específicas e uma imagem definida que o diferencie dos demais.

Sabe-se que devido à facilidade e rapidez com que os atributos são facilmente copiados, é importante desenvolver uma vantagem competitiva sustentável, que possibilite uma posição que não possa ser perdida para os concorrentes no curto prazo.

É, pois, de fundamental importância para as empresas prestadoras de serviços, especialmente as organizações hoteleiras, que desejem melhorar sua competitividade, entenderem os aspectos relacionados à satisfação do cliente. 


\section{3 . O que é satisfação de clientes para uma organização hoteleira?}

Segundo Santos (apud HENZ, 2003) satisfação de clientes é um processo de avaliação que é influenciado pelos desejos e expectativas do consumidor quanto à qualidade e desempenho do produto ou serviço que está sendo comprado ou utilizado.

Altos índices de satisfação, de acordo com Anderson et al. (apud KLEIN, 2003), geram, entre outros benefícios, incremento da lealdade dos clientes, pois a lealdade cresce à medida que aumenta a satisfação e clientes satisfeitos tendem a aceitar melhor o aumento de preços e pagar mais caro.

A satisfação do cliente fornece muitos benefícios para uma empresa e níveis mais altos de satisfação resultam em maior fidelidade. No longo prazo é mais lucrativo manter bons clientes do que constantemente atrair e desenvolver novos clientes para substituir os que saem. Lovelock e Wright (2003) ressaltam que clientes altamente satisfeitos disseminam informações positivas e, na verdade, tornam-se um anúncio ambulante e falante para uma empresa, o que reduz o custo para atrair novos clientes.

Para entender as expectativas dos clientes em relação a um serviço, é importante perceber que, como mencionado pelos autores, quando os clientes avaliam a qualidade de um serviço, eles o estão julgando em função de algum padrão interno que existia antes da experiência de serviço. Esse padrão interno para julgar a qualidade é a base para as expectativas do cliente.

Experiências anteriores, informações de terceiros, propaganda, promessas explícitas e implícitas dos fornecedores, características do grupo a que pertence, do país de origem, cultura e muitos outros fatores semelhantes estão presentes no indivíduo e contribuem para o desenvolvimento de expectativas em relação ao serviço, formando a imagem do serviço que espera receber, denominado por alguns autores como serviço desejado.

Serviços desejados, de acordo com Lovelock e Wright (2003), constituem o que o cliente entende que possa e deva ser entregue para satisfação de suas necessidades, porém os clientes em sua maioria entendem as limitações das organizações e possuem um nível mínimo de serviços que podem aceitar sem ficarem insatisfeitos, o que constitui o serviço adequado.

Um serviço abaixo do nível adequado gera frustração e descontentamento enquanto um serviço em nível acima do desejado, agradará e surpreenderá o cliente, tornando mais viável a 
conquista de sua lealdade. O problema é obter esse equilíbrio em níveis compatíveis de investimentos e custos.

Clientes marginalmente satisfeitos ou indiferentes podem ser atraídos por concorrentes. Um cliente encantado é mais propenso a permanecer fiel a despeito de ofertas competitivas atraentes. A satisfação do cliente desempenha um papel particularmente crítico em ramos altamente competitivos onde há uma enorme diferença entre a fidelidade de clientes meramente satisfeitos e a de clientes completamente satisfeitos ou encantados (LOVELOCK e WRIGHT, 2003, p. 113).

Quando as expectativas e o desempenho real coincidem, segundo Mowen e Minor (2003), as evidências indicam que os consumidores podem simplesmente não exprimir de maneira consciente seus níveis de satisfação com o produto. Assim, embora a confirmação da expectativa seja um estado positivo, ela quase nunca resulta em sentimentos fortes de satisfação.

A expectativa do cliente e sua satisfação ou insatisfação, conforme os autores, serão os determinantes de sua percepção quanto à qualidade do serviço recebido. As características de qualidade do serviço, a seguir, identificadas por esses autores, podem ser vistas como sendo os atributos em relação aos quais os hóspedes de empreendimentos hoteleiros avaliam o desempenho geral dos serviços:

- Tangíveis - inclui instalações físicas, equipamentos e aparência dos funcionários;

- Confiabilidade - capacidade de o funcionário atuar de maneira segura e precisa;

- Tempo de resposta - atender o hóspede com prontidão;

- Segurança - o conhecimento e a cortesia dos funcionários, bem como sua capacidade de inspirar confiança e conviç̧ão;

- Empatia - capacidade dos funcionários em preocupar-se com as pessoas e oferecer-lhes atenção especial.

\section{A importância da medição do Nível de Satisfação de Clientes}

As empresas de serviço podem seguir duas etapas para o controle da qualidade, conforme Kotler (2000). A primeira é investir na cuidadosa seleção e treinamento de pessoal e a segunda é monitorar o nível de satisfação dos clientes.

As considerações dos vários autores citados neste artigo mostram que o conhecimento e a análise dos níveis de satisfação do consumidor para monitorar a qualidade e construir 
diferenciais competitivos se revestem da maior importância. Uma das alternativas que podem servir como base para esse conhecimento, no caso de hotéis, é a pesquisa de satisfação.

Os objetivos de uma pesquisa sobre percepções de clientes, segundo Albrecht (1992) são identificar as características do produto que são cruciais para a sua aceitação pelo cliente e isolar as características que podem formar a base de uma diferenciação bem sucedida de seu serviço em relação a outros existentes no mercado.

A pesquisa de satisfação auxilia a organização a entender as expectativas de qualidade do cliente em relação aos serviços prestados por ela. Considerando que a qualidade está nos olhos do observador (cliente), será difícil saber como os clientes definem qualidade sem que isso lhes seja perguntado. (KOTLER, 2000)

Na visão de Engel, Blackwell e Miniard (2000), um sistema de feedback do cliente é um imperativo absoluto e deve servir como insumo para o aprimoramento constante. Ressaltam, ainda, que a maioria dos que estão insatisfeitos, nunca reclama ou se comunica diretamente com a empresa. A opinião do consumidor deve, antes de tudo, ser solicitada.

Neste momento, cabe uma reflexão sobre o alerta do pensador Joe Cullen:

Neste próximo milênio, as tendências indicam que permanecerão no mercado apenas dois tipos de empresas. Aquelas que investiram maciçamente em qualidade, numa preocupação constante com a satisfação de seus clientes, e as outras que não existirão mais (CULLEN, apud BARROS, 1999, p. 3).

\section{Metodologia}

Para a medição do nível de satisfação de clientes é necessário identificar os prováveis itens considerados como fatores críticos de sucesso e respectivos atributos, e para isso, foi realizada uma pesquisa composta por duas fases:

Fase 1: Para estabelecer os fatores críticos de sucesso e seus atributos, realizou-se uma pesquisa exploratória para coleta de dados e informações. A partir de entrevistas não estruturadas com 2 gerentes de hotéis de categoria super luxo, um da cidade de São Paulo e outro da cidade de Campinas e 3 professores especialistas de curso de pósgraduação em Administração Hoteleira de um Centro Universitário da cidade de São Paulo. 
A questão central apresentada aos entrevistados foi “Quais são os fatores críticos de sucesso e respectivos atributos de um hotel de negócios?”.

Fase 2: Para a validação dos fatores e atributos definidos na Fase 1 foi realizada pesquisa descritiva, cuja metodologia seguiu os seguintes procedimentos:

a) Seleção de um hotel de categoria super luxo;

b) Adaptação dos fatores críticos de sucesso e respectivos atributos para o hotel selecionado. Foram considerados para pesquisa os serviços administrativos, as refeições, as acomodações privativas e os ambientes de lazer. Outros serviços como, por exemplo, ambientes para realização de eventos, reuniões empresariais e sociais não foram avaliados;

c) Seleção de software para tabulação e análise dos resultados;

d) Estruturação e diagramação do questionário com 45 questões. No questionário foram dadas alternativas aos clientes, dentro de uma escala de avaliação, para assinalar sua opinião com respeito a um fator de sucesso ou atributos;

e) Aplicação do questionário junto aos hóspedes:

- A estratégia adotada para abordagem do hóspede foi deixar a pesquisa, juntamente com uma carta de esclarecimento, no próprio apartamento, para que ele a encontre após seu retorno ao hotel, ao final dos compromissos diários. O serviço de governança encarregou-se de adequar as pesquisas em língua inglesa para os hóspedes estrangeiros e em língua portuguesa para os hóspedes brasileiros.

- A distribuição dos questionários foi feita às segundas-feiras, pois normalmente a estada dos hóspedes inicia-se neste dia. Foram distribuídos aleatoriamente, durante o período da pesquisa, 12 questionários a cada segunda-feira, até completar o total de 200;

f) Análise dos resultados e emissão dos relatórios.

A pesquisa foi realizada em um hotel de categoria super luxo, localizado na cidade de Campinas-SP, no período de 01/08/05 a 30/11/05. O hotel possui 63 apartamentos e a taxa de ocupação média, nesse período, foi de 68,2\%. 


\subsection{Questionário utilizado na pesquisa - fase 2}

A estrutura do questionário utilizado para obtenção das opiniões e informações dos hóspedes do Hotel pesquisado levou em conta os seguintes aspectos:

a) Na saída do hotel, a maioria dos hóspedes está se dirigindo para vôo de retorno ou outros compromissos, o que poderia gerar recusas em responder a questionários longos ou com muitas questões de análise.

b) O questionário poderia ser respondido diretamente na tela de um computador. Entretanto duas situações apresentam-se como empecilhos a esse procedimento:

- Seria necessário convencer o hóspede a encaminhar-se ao computador, o que poderia dar-lhe a impressão de um tempo mais longo para resposta.

- E o hotel não dispõe de uma área especial com vários computadores, acarretando assim a utilização deste único equipamento por um usuário de cada vez. Aqueles que quisessem participar teriam que aguardar sua vez, e provavelmente, a amostra disposta a colaborar seria bastante reduzida.

Ao final das questões, havia um espaço para acrescentar manifestações espontâneas, cujo preenchimento não era obrigatório. Para conhecer o perfil do entrevistado, também foi solicitado o preenchimento de informações inerentes ao hóspede que poderia se identificar ou não. O questionário utilizado está apresentado no Apêndice 1.

\subsection{Aspectos do software utilizado}

Para a tabulação e análise dos resultados da pesquisa realizada na Fase 2 utilizou-se um software denominado XisView, desenvolvido para medição do nível de satisfação de clientes.

O instrumento integrou a pesquisa desde a geração do projeto e dos objetivos, a determinação de fatores e atributos a avaliar, até o desenvolvimento de questões e estruturação do questionário e possibilita:

- Seguir um processo seqüencial de parametrização;

- Identificar e selecionar o que é importante saber do mercado e dos clientes;

- Enviar o questionário via e-mail;

- Realizar a pesquisa diretamente no sistema; 
- Obter medidas de proporção de clientes satisfeitos, erro padrão, proporção populacional, coeficiente de mudança;

- Visualizar a qualquer instante as informações mais relevantes;

- Comparar o desempenho do ISC - Índice de Satisfação dos Clientes em tempos específicos;

- Emitir os resultados em relatórios e gráficos.

A avaliação é efetuada por meio do questionário sobre os fatores críticos de sucesso de relacionamento de cliente com a estrutura operacional ou com os serviços.

O software faz a medida do escore amostral que tem uma graduação de 1 a 5 relacionada a avaliação do cliente, onde 1 = ruim, 2 = regular, 3 = bom, 4 = muito bom e 5 = excelente.

\section{Análise dos resultados}

A primeira fase da pesquisa tinha por objetivo identificar os fatores críticos de sucesso e seus respectivos atributos, a serem considerados na avaliação do nível de satisfação dos clientes de um hotel de negócios. O Quadro 1, a seguir, demonstra os resultados obtidos.

Quadro 1 - Fatores críticos de sucesso de um hotel de categoria super luxo e seus atributos

\begin{tabular}{|l|l|}
\hline \multicolumn{1}{|c|}{ Fatores } & \multicolumn{1}{c|}{ Atributos } \\
\hline \multirow{4}{*}{ Localização } & 1 - Localização \\
\cline { 2 - 2 } & 2 - Acesso \\
\hline \multirow{5}{*}{ Instalações Físicas } & 3 - Sinalização e circulação da área social \\
\cline { 2 - 2 } & 4 - Aspecto visual \\
\cline { 2 - 2 } & 5 - Iluminação e ventilação da área social \\
\cline { 2 - 2 } & $\begin{array}{c}\text { 6 - Facilidades construtivas para o Portador de Necessidades } \\
\text { Especiais }\end{array}$ \\
\cline { 2 - 2 } Atmosfera Interna & 7 - Conservação e manutenção \\
\hline \multirow{2}{*}{ Internet e Telefonia } & 8 - Conforto térmico dos ambientes comuns \\
\cline { 2 - 2 } & 9 - Decoração dos ambientes \\
\hline \multirow{3}{*}{ Atendimento da Recepção } & 10 - Sistema de telefonia \\
\cline { 2 - 2 } & 11 - Facilidade de conexão à Internet \\
\hline \multirow{4}{*}{ Acomodações privativas } & 12 - Cortesia \\
\cline { 2 - 2 } & 13 - Clareza e Objetividade \\
\cline { 2 - 2 } & 14 - Comprometimento \\
\cline { 2 - 2 } & 15 - Conforto térmico \\
\cline { 2 - 2 } & 16 - Conforto sonoro \\
\hline
\end{tabular}




\begin{tabular}{|c|c|}
\hline \multirow{3}{*}{ Higiene e Limpeza } & 18 - Roupas de cama, mesa e banho \\
\hline & 19 - Ambientes de circulação e privativos \\
\hline & 20 - Toillets higienizados \\
\hline \multirow{3}{*}{ Qualidade das refeições } & 21 - Tempero e Aparência \\
\hline & 22 - Variedade das refeições \\
\hline & 23 - Variedade do café da manhã \\
\hline \multirow{3}{*}{ Infra-estrutura do restaurante } & 24 - Disponibilidade do atendimento \\
\hline & 25 - Conforto sonoro \\
\hline & 26 - Espaço, decoração e requinte \\
\hline \multirow{3}{*}{ Segurança } & 27 - Funcionários exclusivos \\
\hline & 28 - Circuito fechado de TV e vídeo \\
\hline & 29 - Apoio em urgência médica \\
\hline \multirow{5}{*}{ Instalações de lazer } & 30 - Fitness center \\
\hline & 31 - Piscina \\
\hline & $32-$ Sauna \\
\hline & 33 - Sala de jogos \\
\hline & 34 - Ambiente de Happy Hour \\
\hline \multirow{2}{*}{ Cortesia } & 35 - Celular sem aluguel \\
\hline & 36 - Acesso à Internet no apartamento \\
\hline Estacionamento & 37 - Serviço de manobrista \\
\hline \multirow{4}{*}{ Práticas comerciais } & 38 - Níveis de preços \\
\hline & 39 - Formas de pagamento \\
\hline & 40 - Facilidades de reserva \\
\hline & 41 - Programa de Fidelização \\
\hline
\end{tabular}

Fonte: Elaborado pelos autores com base na pesquisa exploratória realizada com gerentes de hotéis e especialistas em administração hoteleira.

A segunda fase da pesquisa objetivava validar os fatores e atributos identificados na fase 1 , como adequados para avaliar o nível de satisfação dos hóspedes de um hotel de categoria super luxo.

As tabelas a seguir mostram os resultados dessa pesquisa e sua estratificação por sexo, nacionalidade, idade e tipo de estadia. A Tabela 1 apresenta os dados gerais da pesquisa, destacando que a taxa de retorno entre o número de questionários entregues e devolvidos foi de $45 \%$.

Tabela 1 - Dados Gerais da Pesquisa

\begin{tabular}{c|c|c}
\hline & $\mathrm{n}$ & $\%$ \\
\hline Questionários entregues aos hóspedes. & 200 & 100 \\
\hline Questionários devolvidos. & 90 & 45 \\
\hline Questionários utilizados. & 76 & 38 \\
\hline
\end{tabular}

A taxa de retorno não foi a esperada, pois os hóspedes comumente se desculpavam alegando falta de tempo no início da manhã por já estarem preocupados com seus compromissos profissionais e cansados no retorno ao apartamento. 
Os 14 questionários que não foram utilizados apresentavam questões sem respostas no verso, pois provavelmente, os respondentes não perceberam que havia uma continuação.

A Tabela 2 apresenta o nível de satisfação mínimo, máximo e médio dos hóspedes pesquisados. O nível de satisfação de clientes é um estado decorrente do atendimento das necessidades e expectativas dos mesmos durante relacionamentos transacionais. A avaliação ruim, regular, bom, muito bom ou excelente é puramente um ponto em uma escala, que estabelece uma indicação da existência, ou não, de focos de insatisfação, os quais poderão ser determinantes do retorno dos clientes. Enfim, o nível de satisfação é um importante indicador das perspectivas de fidelização da clientela.

Tabela 2 - Nível de Satisfação Geral dos Hóspedes

\begin{tabular}{c|c}
\hline Nível de satisfação mínimo & $29,7 \%$ \\
\hline Nível de satisfação máximo & $99,1 \%$ \\
\hline Nível médio de satisfação & $83,3 \%$ \\
\hline
\end{tabular}

Para se quantificar a satisfação dos clientes, foi calculado um escore médio através de uma média aritmética simples das respostas. Assim, para calcularmos o escore médio de toda a amostra, somamos os valores de todas as respostas, de acordo com a graduação de 1 a 5 , e dividimos pelo total de respostas colhidas. Quando separamos as respostas por grupos, por exemplo, por sexo, foi feita a média apenas dentro de cada grupo.

Como as respostas variavam segundo os valores: $1=$ ruim, $2=$ regular, $3=$ bom, $4=$ muito bom e 5 = excelente, isso significa que quanto mais o escore médio se aproximasse de 5, é porque a avaliação estava mais próxima de excelente. Quanto mais próximo de 1 estivesse o escore médio, mais próxima de ruim teria sido a avaliação nesse caso.

Baseando-se nos escores médios, foi definido o “nível de satisfação”, que era obtido transformando-se o escore médio numa porcentagem em relação ao escore máximo. Ou seja, se após fazer a média aritmética de todas as respostas de uma pessoa, encontrássemos o valor 4 (esse seria seu escore médio), dividíamos essa média por 5 para encontrarmos que porcentagem essa média representa. Nesse caso 0,8 e definiríamos o nível de satisfação dessa pessoa como sendo $80 \%$.

É importante salientar que o nível de satisfação máximo possível era de 100\%, caso todas as respostas fossem iguais a 5 e o nível de satisfação mínimo possível era de 20\%, caso todas as respostas fossem iguais a 1. 
Na pesquisa o escore médio amostral foi de 4,165 que equivale a 83,3\%, o escore mínimo foi de 1,485 que corresponde a $29,7 \%$ e o escore máximo foi de 4,955 que equivale a 99,1\%.

A Tabela 3 mostra o total de questões respondidas, 3.420, que é o resultado do produto das 76 pesquisas aplicadas com 45 questões cada uma. Verifica-se que foram assinaladas 3,4\% das respostas entre ruim e regular e 22,6\%, como “não sei”.

Os atributos assinalados com a opção “não sei” referem-se especialmente aos fatores qualidade das refeições, segurança, instalações de lazer, estacionamento e práticas comerciais, pois provavelmente não foram utilizados ou não eram conhecidos pelos hóspedes. Isto se justifica, pois $77,6 \%$ dos hóspedes tinham como motivação de estada negócios ou convenções, conforme mostra a Tabela 4.

Tabela 3 - Freqüência das respostas

\begin{tabular}{c|c|c}
\hline Tipo de resposta & Freqüência & $\mathbf{\%}$ \\
\hline Ruim & 24 & 0,7 \\
\hline Regular & 93 & 2,7 \\
\hline Bom & 410 & 12,0 \\
\hline Muito bom & 925 & 27,0 \\
\hline Excelente & 1182 & 34,6 \\
\hline Não sei & 773 & 22,6 \\
\hline Prefiro não responder & 13 & 0,4 \\
\hline Total de Questões & $\mathbf{3 4 2 0}$ & $\mathbf{1 0 0}$ \\
\hline
\end{tabular}

A Tabela 4 mostra o perfil dos 76 hóspedes pesquisados por idade, nacionalidade, motivação de estada e sexo.

Tabela 4-Perfil dos hóspedes

\begin{tabular}{c|c|c|c}
\hline \multicolumn{2}{c|}{ Perfil dos Hóspedes } & Quantidade & $\mathbf{\%}$ \\
\hline \multirow{4}{*}{ Idade } & Até 30 anos & 19 & 25,0 \\
\cline { 2 - 4 } & De 31 a 45 anos & 28 & 36,8 \\
\cline { 2 - 4 } & Acima de 45 anos & 29 & 38,2 \\
\hline \multirow{4}{*}{ Nacionalidade } & Americano & 14 & 18,5 \\
\cline { 2 - 4 } & Asiático & 2 & 2,6 \\
\cline { 2 - 4 } & Brasileiro & 58 & 76,3 \\
\cline { 2 - 4 } & Europeu & 2 & 2,6 \\
\hline \multirow{3}{*}{\begin{tabular}{c} 
Estivação de \\
\cline { 2 - 4 }
\end{tabular}} & Negócios & 49 & 64,5 \\
\cline { 2 - 4 } & Convenção & 10 & 13,1 \\
\hline \multirow{2}{*}{ Sexo } & Outros & 17 & 22,4 \\
\cline { 2 - 4 } & Homens & 64 & 84,2 \\
\hline
\end{tabular}


A Tabela 5 mostra a estratificação do nível de satisfação (NS) dos hóspedes pesquisados por idade, nacionalidade, tipo de estada e sexo. Verifica-se que o NS mínimo foi atribuído por um hóspede acima de 45 anos, americano, com estada para negócios e do sexo masculino e que o NS máximo, foi atribuído por um hóspede de 31 a 45 anos, brasileiro, com estada para convenção e do sexo feminino.

Tabela 5 - Estratificação do Nível de Satisfação dos Hóspedes

\begin{tabular}{c|c|c|c|c}
\hline \multicolumn{2}{c|}{ Perfil do Hóspede } & NS Mínimo & NS Máximo & NS Médio \\
\hline \multirow{4}{*}{ Idade } & Até 30 anos & $33,9 \%$ & $88,8 \%$ & $63,0 \%$ \\
\cline { 2 - 5 } & De 31 a 45 anos & $41,3 \%$ & $\mathbf{9 9 , 1 \%}$ & $70,9 \%$ \\
\cline { 2 - 5 } & Acima de 45 anos & $\mathbf{2 9 , 7 \%}$ & $84,6 \%$ & $61,1 \%$ \\
\hline \multirow{4}{*}{ Nacionalidade } & Americano & $\mathbf{2 9 , 7 \%}$ & $92,1 \%$ & $63,4 \%$ \\
\cline { 2 - 5 } & Asiático & $57,2 \%$ & $61,5 \%$ & $59,4 \%$ \\
\cline { 2 - 5 } & Brasileiro & $33,9 \%$ & $\mathbf{9 9 , 1 \%}$ & $65,3 \%$ \\
\cline { 2 - 5 } Tipo de Estadia & Europeu & $\mathbf{7 8 , 1 \%}$ & $\mathbf{8 3 , 6 \%}$ & $\mathbf{8 0 , 9 \%}$ \\
\cline { 2 - 5 } & Negócios & $\mathbf{2 9 , 7 \%}$ & $92,1 \%$ & $65,1 \%$ \\
\cline { 2 - 5 } & Convenção & $54,6 \%$ & $\mathbf{9 9 , 1 \%}$ & $68,7 \%$ \\
\hline \multirow{4}{*}{ Sexo } & Outros & $33,9 \%$ & $88,8 \%$ & $63,4 \%$ \\
\cline { 2 - 5 } & Homens & $\mathbf{2 9 , 7 \%}$ & $92,1 \%$ & $64,5 \%$ \\
\hline
\end{tabular}

A Tabela 6 resume a estratificação do nível médio de satisfação (NS) da pesquisa por fator crítico de sucesso e seus respectivos atributos. Com os resultados apresentados nesta tabela, os responsáveis pelo hotel podem identificar em que aspectos a organização atende as necessidades dos clientes, bem como aqueles que não atende. Por exemplo, o fator Cortesia 1 mostra o NS médio de 92\% que indica que as ações do hotel são bem aceitas pelos hóspedes, por outro lado, o fator Instalações de Lazer apresenta NS médio de 66,1\% que mostra a necessidade de ações de inovações e melhorias. Observa-se neste fator que uma ação tomada anteriormente referente à disponibilização de Fitness Externo foi bem avaliada pelos hóspedes. 
Tabela 6 - Estratificação do nível médio de satisfação por fator crítico de sucesso e atributo

\begin{tabular}{|c|c|c|c|}
\hline Fatores & $\begin{array}{l}\text { NS Médio } \\
\text { (\%) }\end{array}$ & Atributos & $\begin{array}{c}\text { NS Médio } \\
(\%)\end{array}$ \\
\hline \multirow{2}{*}{ Localização } & \multirow{2}{*}{80,8} & Localização & 83,4 \\
\hline & & Acesso & 78,1 \\
\hline \multirow{5}{*}{ Instalações } & \multirow{5}{*}{78,8} & Sinalização e Circulação & 78,6 \\
\hline & & Aspecto Visual & 85,6 \\
\hline & & Iluminação e Ventilação & 81,8 \\
\hline & & Acesso ao Portador de Neces. Espec. & 69,7 \\
\hline & & Conservação e Manutenção & 78,3 \\
\hline \multirow{2}{*}{ Atmosfera } & \multirow{2}{*}{82,7} & Conforto térmico & 84,0 \\
\hline & & Decoração & 81,5 \\
\hline \multirow{2}{*}{ Comunicações } & \multirow{2}{*}{82,4} & Funcionamento & 83,1 \\
\hline & & Facilidade de conexão & 81,7 \\
\hline \multirow{3}{*}{$\begin{array}{l}\text { Atendimento da } \\
\text { Recepção }\end{array}$} & \multirow{3}{*}{87,5} & Cortesia & 90,2 \\
\hline & & Clareza e Objetividade & 86,0 \\
\hline & & Comprometimento & 86,2 \\
\hline \multirow{3}{*}{$\begin{array}{l}\text { Acomodações } \\
\text { Privativas }\end{array}$} & \multirow{3}{*}{82,3} & Conforto Térmico & 82,8 \\
\hline & & Conforto Sonoro & 80,2 \\
\hline & & Espaço e Decoração & 83,6 \\
\hline \multirow{3}{*}{ Higiene e Limpeza } & \multirow{3}{*}{89,3} & Higiene de Roupas & 88,6 \\
\hline & & Higiene de Ambientes & 88,1 \\
\hline & & Higiene de Toillets & 91,0 \\
\hline \multirow{4}{*}{$\begin{array}{l}\text { Qualidade das } \\
\text { Refeições }\end{array}$} & \multirow{4}{*}{81,8} & Tempero e Aparência & 82,7 \\
\hline & & Variedade das Refeições & 77,4 \\
\hline & & Variedade do café da manhã & 83,4 \\
\hline & & Room Service 24 horas & 83,9 \\
\hline \multirow{3}{*}{$\begin{array}{l}\text { Infra-Estrutura do } \\
\text { Restaurante }\end{array}$} & \multirow{3}{*}{81,7} & Disponibilidade & 82,4 \\
\hline & & Conforto sonoro & 82,9 \\
\hline & & Espaço e decoração & 80,0 \\
\hline \multirow{3}{*}{ Segurança } & \multirow{3}{*}{81,4} & Funcionários exclusivos & 80,0 \\
\hline & & Circuito Interno TV & 81,2 \\
\hline & & Urgência Médica & 82,8 \\
\hline \multirow{4}{*}{ Instalações de Lazer } & \multirow{4}{*}{66,1} & Fitness Interno & 52,3 \\
\hline & & Fitness Externo & 82,5 \\
\hline & & Condições da Piscina & 64,5 \\
\hline & & Condições da Sauna & 65,3 \\
\hline \multirow{5}{*}{ Cortesia 1} & \multirow{5}{*}{92,0} & Uso de celular & 86,2 \\
\hline & & Acesso Internet & 88,1 \\
\hline & & Frigobar & 96,4 \\
\hline & & Welcome Drink & 96,6 \\
\hline & & Welcome coffee & 92,6 \\
\hline & & Happy Hour & 91,0 \\
\hline Cortesia 2 & 91,3 & Cesta de Maçãs & 91,6 \\
\hline Estacionamento & 87,5 & Serviço de Manobrista & 87,5 \\
\hline & & Preços praticados & 77,0 \\
\hline Práticas Comerciais & 83,3 & Formas de pagamento & 86,1 \\
\hline & & Facilidade de reserva & 87,0 \\
\hline
\end{tabular}




\section{Conclusões}

A alocação dos recursos em investimentos que resultem em valor para o cliente somente é possível se as necessidades, desejos e valores destes forem corretamente identificados, o que é possível a partir do conhecimento dos fatores críticos de sucesso para o negócio, que sirvam de base para o questionário de medida de níveis de satisfação de clientes.

Ao ser interrogado, um entrevistado avaliou os itens que lhe foram apresentados, sendo que muitas vezes o ponto de maior importância ou descontentamento em sua opinião, poderá não ser apontado se o item não estiver relacionado no instrumento de pesquisa, deturpando o resultado. A conseqüência nesta situação é que a decisão sobre investimentos, para melhor adequação do negócio às expectativas dos clientes, muito provavelmente será equivocada, resultando em gastos sem o conseqüente incremento de resultado no negócio.

Ressalta-se que não se mede somente por medir, ou não se desenvolve processos de identificação de fatores críticos de sucessos e atributos somente por curiosidade. Isso pressupõe ações de correção e de melhorias, pois sistemas de medição do nível de satisfação oferecem a possibilidade de estabelecer a excelência em padrões de serviço. Constituindo-se em referência clara às práticas do mercado.

O ponto fundamental para que uma pesquisa de satisfação atenda aos objetivos a que se propõe é a correta identificação dos atributos que serão apresentados ao cliente para avaliação. Esta era a contribuição principal deste trabalho, ao oferecer um conjunto de fatores e seus respectivos atributos para contribuir com a disseminação da prática do monitoramento da avaliação do nível de satisfação dos hóspedes de hotéis, particularmente, neste estudo, daqueles da categoria super luxo. Esses fatores e atributos foram apresentados no Quadro 1. Além disso, procedeu-se a aplicação empírica dos fatores identificados, a partir de uma metodologia de aplicação, descrita no item 5 - Fase 2. Os resultados permitiram validar os fatores e atributos encontrados e apresentados no quadro 1.

Com a realização da pesquisa, a administração do hotel pode monitorar o nível de satisfação dos hóspedes, obtendo maior conhecimento sobre suas necessidades e expectativas. 
A pesquisa apresentou resultados que permitem avaliar, onde o Hotel deve fazer investimentos em melhorias e diferenciais que sejam percebidos e valorizados pelos hóspedes, possibilitando decisões com segurança e menor risco.

\section{Referências Bibliográficas}

ALBRECHT, Karl. 1992. Revolução nos serviços: como as empresas podem revolucionar a maneira de tratar seus clientes. São Paulo: Pioneira.

BARROS, Claudius D’Artagnan C. de. Excelência em serviços: uma questão de sobrevivência no mercado. Rio de Janeiro: Qualitymark, 1999.

DAY, George S. 2001. A empresa orientada para o mercado: compreender, atrair e manter clientes valiosos. Tradução de Nivaldo montigelli Jr. Porto Alegre: Boockman.

ENGEL, James F; BLACKWELL, Roger D. e MINIARD, Paul W. 2000, Comportamento do consumidor. Rio de Janeiro: Livros Técnicos e Científicos Editora.

HENZ, Miriam Mariani. 2003. Programa de relacionamento viva claro: avaliação geral dos benefícios para a empresa e clientes com base nas atitudes e comportamentos dos clientes. Dissertação de Mestrado, Programa de Administração da Universidade Federal do Rio Grande do Sul. Porto Alegre.

KLEIN, Marcus Vinicius. 2003. Identificação do nível de relacionamento entre a claro digital e seus clientes corporativos. Dissertação de Mestrado, Programa de Administração da Universidade Federal do Rio Grande do Sul. Porto Alegre.

KOTLER, Philip. 2000. Administração de marketing. São Paulo: Prentice Hall.

KOTLER, Philip; HAYES, Thomas e BLOOM, Paul N. 2000. Marketing de serviços profissionais. São Paulo: Prentice Hall.

LOVELOCK, Christopher e WRIGHT, Lauren. 2003. Serviços marketing e gestão. São Paulo: Saraiva.

MOWEN, John C. e MINOR, Michael S. 2003. Comportamento do consumidor. São Paulo: Prentice Hall.

Recebido em: 20/10/2006 (1 ${ }^{\text {a }}$ versão) 06/03/2007 ( $2^{\mathrm{a}}$ versão)

Aprovado em: 19/03/2007 


\section{APÊNDICE 1}

\section{Pesquisa: Medição do Nível de Satisfação de Clientes}

Por favor, preencha a coluna da direita, com o número correspondente à alternativa escolhida, conforme escala abaixo:

\begin{tabular}{|c|c|c|c|c|c|c|}
\hline $\begin{array}{c}1- \\
\text { Ruim }\end{array}$ & $\begin{array}{c}2- \\
\text { Regular } \\
\end{array}$ & $\begin{array}{c}3- \\
\text { Bom }\end{array}$ & $\begin{array}{c}4 \text { - Muito } \\
\text { Bom }\end{array}$ & $\begin{array}{c}5 \text { - } \\
\text { Excelente } \\
\end{array}$ & 6 - Não Sei & $\begin{array}{c}7 \text { - Prefiro não } \\
\text { responder }\end{array}$ \\
\hline
\end{tabular}

\section{Como o Senhor (a) avalia:}

\begin{tabular}{|c|c|c|}
\hline \multirow{2}{*}{ Localização } & 1 - A localização do hotel. & \\
\hline & 2 - O acesso ao hotel. & \\
\hline \multirow{5}{*}{$\begin{array}{l}\text { Instalações } \\
\text { Físicas }\end{array}$} & 3 - A sinalização e a circulação da área social do hotel. & \\
\hline & 4 - O aspecto visual das instalações. & \\
\hline & 5 - A iluminação e ventilação da área social. & \\
\hline & 6 - As facilidades construtivas para o portador de necessidades especiais. & \\
\hline & 7 - A conservação e manutenção das instalações físicas. & \\
\hline \multirow{2}{*}{$\begin{array}{l}\text { Atmosfera } \\
\text { Interna }\end{array}$} & 8 - O conforto térmico dos ambientes comuns. & \\
\hline & 9 - A decoração dos ambientes. & \\
\hline \multirow{2}{*}{$\begin{array}{l}\text { Internet e } \\
\text { Telefonia }\end{array}$} & 10 - O funcionamento do sistema de telefonia. & \\
\hline & 11 - A facilidade de conexão à Internet. & \\
\hline \multirow{3}{*}{$\begin{array}{l}\text { Atendimento da } \\
\text { Recepção }\end{array}$} & 12 - A cortesia no atendimento da recepção. & \\
\hline & 13 - A clareza e objetividade no atendimento. & \\
\hline & 14 - O comprometimento dos funcionários. & \\
\hline \multirow{3}{*}{$\begin{array}{c}\text { Acomodações } \\
\text { privativas }\end{array}$} & 15 - O conforto térmico do apartamento. & \\
\hline & 16 - O conforto sonoro do apartamento. & \\
\hline & 17 - O espaço, a decoração e o conforto do apartamento. & \\
\hline \multirow{3}{*}{$\begin{array}{l}\text { Higiene e } \\
\text { Limpeza }\end{array}$} & 18 - A higiene das roupas de cama, mesa e banho. & \\
\hline & 19 - A limpeza e higiene dos ambientes de circulação e privativos. & \\
\hline & 20 - A higiene e disponibilidade dos acessórios dos toillets. & \\
\hline \multirow{4}{*}{$\begin{array}{l}\text { Qualidade das } \\
\text { refeições }\end{array}$} & 21 - O tempero e a aparência dos alimentos nas refeições. & \\
\hline & 22 - A variedade de opções nas refeições. & \\
\hline & 23 - A variedade dos itens no café da manhã. & \\
\hline & $24-$ Room Service 24 horas. & \\
\hline \multirow{3}{*}{$\begin{array}{l}\text { Infra-estrutura } \\
\text { do restaurante }\end{array}$} & 25 - A disponibilidade de atendimento do restaurante. & \\
\hline & 26 - O conforto sonoro do restaurante. & \\
\hline & 27 - O espaço, a decoração e o requinte do restaurante. & \\
\hline \multirow{3}{*}{ Segurança } & 28 - Os funcionários dedicados à segurança. & \\
\hline & 29 - A vigilância do circuito interno de TV / Vídeo. & \\
\hline & 30 - A prontidão em caso de urgência médica. & \\
\hline \multirow{4}{*}{$\begin{array}{c}\text { Instalações de } \\
\text { Lazer }\end{array}$} & 31 - As instalações e os equipamentos do fitness center. & \\
\hline & 32 - As instalações e os equipamentos da Academia Cambuí Fitness. & \\
\hline & 33 - As condições de uso e as instalações da piscina. & \\
\hline & 34 - As condições de uso e as instalações da sauna. & \\
\hline
\end{tabular}




\begin{tabular}{|c|l|l|}
\hline \multirow{4}{*}{ Cortesia } & 35 - O uso de celular sem aluguel. & \\
\cline { 2 - 3 } & 36 - O terminal de acesso à Internet no apartamento. & \\
\cline { 2 - 3 } & 37 - O consumo livre do frigobar. & \\
\cline { 2 - 3 } & 38 - O welcome drink. & \\
\cline { 2 - 3 } & 39 - O welcome coffee (mesa com café, chás, bolos e petit-fours). & \\
\cline { 2 - 3 } & 40 - O Happy Hour (mesa de frios com música ao vivo). & \\
\cline { 2 - 3 } & 41 - A cesta de maçãs. & \\
\hline Estacionamento & 42 - O serviço de manobrista do hotel. & \\
\hline \multirow{2}{*}{$\begin{array}{c}\text { Práticas } \\
\text { Comerciais }\end{array}$} & 43 - Os níveis de preços praticados pelo hotel. & 44 - As formas de pagamento praticadas pelo hotel. \\
\cline { 2 - 3 } & 45 - A facilidade no procedimento de reserva. & \\
\hline
\end{tabular}

\section{Manifestações espontâneas:}

Hóspede (nome opcional):

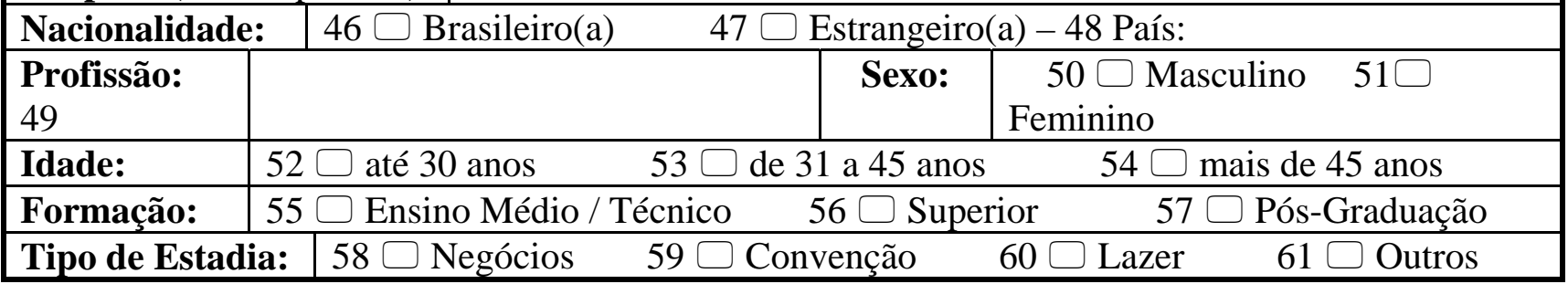

\begin{tabular}{|l|l}
\hline $\begin{array}{l}\text { Pesquisa aplicada em: } \\
62\end{array}$ & Campinas, __ de __ de 2005. \\
\hline
\end{tabular}

